Examination of Growth.-The specimens removed were submitted to Dr. Swan, who made the following uncertain report, the cause of the uncertainty possibly being the failure to secure a portion of the base of the growth.

Pathologic Report on First Specimen.-"A few fragments of tissue removed from the external urinary meatus. The tissue is composed of a surface epithelium of the stratified squamous type lying on a connective tissue groundwork. The majority of the sections are of such a nature that no opinion can be given as to their character, but in one slide the con. nective tissue portion of the specimen is composed of a loose reticulum of cells of varying type mixed with an extensive exudate of red blood-corpuscles. Many of the cells, I believe, are epithelial cells, and I think the tumor is malignant, but I am not prepared to give an opinion as to its proper classifi. cation. Diagnosis: questionable."

Subsequent History.-The patient was kept under close observation, and seven months later (Dec. 13, 1909), there was distinct evidence of a recurrence of the growth in the shape of an ulceration at its site with raised, hard edges that refused to heal. She was readmitted to the hospital under the belief that the growth was originally and stili malignant, with a view to its thorough destruction. On this occasion a current of 200 to 300 milliamperes was employed for double the previous time, or thirty-four minutes, and with six larger needles completely circling the growth at its base. Both operations were monopolar, that is, the negative pole was a large kaolin pad beneath the patient's back. Special efforts were made at this second operation to reach the highest point of the growth in the urethra with as little loss of muscular tissue as possible.

Pathologic Report on Second Specimen.-The pathologic report on the specimen removed at this time is as follows: "Three fragments of tissue removed near the orifice of the urethra, submitted for examination. The largest of these fragments is composed of very much hypertrophied squamous epithelium, which is in one place thrown into numerous folds so that it resembles the duct of a gland. Many of the cells of this epithelium are hydropic. No place can be found in which this epithelium extends into the underlying connective tissue, but the connective tissue just beneath it is the seat of a very well-marked round-celled infiltration, and these cells are principally of the plasma. cell type. The tissue is markedly congested, and in some places there is free hemorrhage. The round-celled infiltration above referred to is seen in scattered areas throughout the connective tissue, here and there associated with polymorphonuclear cells. There are a great many new blood-vessels in the tissue. One of the smaller bits is elliptical in outline, surrounded throughout its entire extent with a stratified squamous epithelium which does not dip down into the underlying connective tissue. This connective tissue is rich in blood-vessels, which are filled with blood, and shows numerous fibroblasts, and areas of small round-eelled infiltration of the plasma cell type, mixed with lymphocytes. The third piece is composed of masses of round cells of varying type; polymorphonuclears, lymphocytes, plasma cells and fragmented nuclei. The tissue contains numerous blood-vessels with fairly thick walls. In several places there is free hemorrhage. In one part of this piece the endothelial cells form ing the walls of the blood-vessels appear to be proliferating. Diagnosis: infective granuloma (?)."

Third Operation.-On Feb. 24, 1910, the patient was admitted a third time for the destruction of three nodules of bright color at the meatus. A current of from 100 to 150 milliamperes was used for twelve minutes, with three needles.

Result.- - Her progress thereafter was steady, the parts closing in with tissue of normal color, somewhat retracted, but with complete control of the bladder and absence of unpleasant sensations, except a hypogastric discomfort for a time, apparently referable to the bladder. At present, ten months after the last operation, there is smooth scar tissue occupying the whole site of the growth, the external layer being regenerated mucous membrane by peripheral budding. The urethra seems healthy and of normal caliber, with the meatus retracted about one inch. This retraction has tilted the anterior wall of the vagina outward at the urethral orifice. The patient's unpleasant sensations on micturition have ceased and she has good control over the bladder. No evidence of a return of the disease can be found, and she has gained in weight and color.

903 Professional Building.

\section{EARLY DIAGNOSIS OF GALL-STONE DISEASE}

\section{C. COLEMAN, M.D.}

Instructor in Principles of Surgery and Clinical Surgery in the Medical College of Virginia RICHMOND, VA.

The success of surgery of the bile-tract within the last ten years is due to more effective cooperation between the surgeon and the general practitioner, to closer observation of pathology, and to the contributions of experimental medicine. The opportunity of the surgeon to study pathology at the operating-table has brought about a clearer understanding of the significance of syrnptoms which heretofore have not been appreciated. The great work done by the Mayos and their associates, by Deaver, Moynihan and others, in calling attention to pathologic conditions found in the living has revolutionized our former conception of gall-stone disease. We now know that gall-stones, instead of being frequently present without symptoms, create a distinct type of clinical phenomena, which in the past we did not properly interpret. The picture of the terminal stage has been too frequently used for a general description of gall-stone disease.

The close association of the organs of the upper abdomen often causes diseases of any of these organs to find expression in the stomach. To assign these stomach symptoms to their real cause requires careful study. Except in ulcer or cancer, the stomach is seldom the seat of primary trouble, though it may be the agent through which distress in many abdominal organs may manifest itself.

The classical picture of gall-stone disease, accompanied by attacks of severe pain radiating to the right shoulder, nausea, vomiting and jaundice, is a late stage and results from complications that a calculous cholecystitis may. cause. It is most unfortunate that these symptoms are still regarded by many as necessary to a diagnosis, thereby delaying proper treatment and prolomging disability. To prevent complications such as adhesions, perforation, obstruction of the common duct and chronic pancreatitis, it is necessary to recognize what Moynihan calls the "inaugural symptoms" of gall-stone disease, and to dismiss from our minds the typical text-book description of gall-stone colic.

Disease of the gall-bladder has its own type of digestive disturbance. According to Graham, we may distinguish four stages in its development and symptomatology.

In the first stage we see mild disturbance of the stomach, which occasions little distress to patients or anxiety to the physician. Irregular attacks of indigestion accompanied by gas formation and a feeling of epigastric constriction or tightness are observed. These discomforts are sudden in their onset and are frequently accompanied by chilliness, belching, regurgitation, or vomiting. Such dyspeptic attacks, sudden, irregular and mild, are as characteristic of early gall-bladder disease, as the typical attacks of gall-stone colic, which may ensue unless the trouble is recognized and proper trentment instituted. 
In the second stage the disease occurs with pain, which may be dull or severe, and is located under the right costal arch. This pain may be aggravated by food, by sudden exertion or deep inspiration, and unless a careful physical examination of the chest is made, the physician may explain the symptoms by a diagnosis of pleurisy. These attacks of pain and dyspeptic disturbances are frequently evanescent in type, and with their going the patient enters on a period of good health.

In the third stage we have attacks of gall-stone colic, and here the diagnosis is easy. It is in this class of cases that the surgeon is most frequently called. These patients come with a well-defined history of sudden, excruciating pain located in the upper part of the abdomen, radiating to the right scapula and attended by nausea and vomiting. We have here, also, gas formation and spasm of the diaphragm; vomiting may give partial or complete relief, though morphin is most frequently required. A characteristic of these attacks is the suddenness of the onset and disappearance. The patient is unable to trace any connection between the beginning of the attack and the taking of food. Even in this advanced stage of the disease there may be a return of perfect health, which may continue for an indefinite period, to be suddenly interrupted in most cases by another severe attack.

The fourth stage represents chronic gall-bladder disease, with further complications of adhesions, obstruetion of the common duct or pancreatitis. The diagnosis is not clear in this type unless the history of the case is carefully studied. 'Too frequently the significance of the symptoms or the urgency of the case is not appreciated until this stage is reached, and in view of former teaching, such a mistake is entirely reasonable.

Unless one has seen patients with gall-stone disease in the first or second stage operated on, it will be difficult for one to appreciate the constancy with which operation in these cases shows pathologic conditions of the gall-bladder. That operation relieves such patients and cures their "dyspepsia," is amply proved by the large number of patients operated on in most of the clinies in this country. These patients, who have definite symptoms of the first or the second stage, and are cured by operation, are the best proof of the association of gastric disturbances with the presence of gall-stones. Occasionally, we see cases in which the gall-bladder is packed with stones, thickened and adherent, and still there have been no symptoms other than the gastric disturbances already mentioned. The following case in the service of Dr. J. Shelton Horsley illustrates this point.

CASE 1.-History.-Mrs. P., aged 37, a thin, emaciated woman, had suffered with stomach trouble and indefinite dyspepsia for the past twenty years. She complained of a "dull, aching, swollen feeling" in the upper abdomen, which sometimes radiated to the right shoulder and was frequently made worse by eating. She had had considerable bloating and beIching. There had been no colic, jaundice, or pain severe enough to require a physician. Vomiting, which occurred only a few times, hrought relief, though she usually obtained relief by drinking hot water. She said, "I have taken a lot of medicine for indigestion, which would relieve me for a while."

Diagnosis and Treatment.-Cholecystitis, with probably enlarged gall-bladder. Operation showed that the gall-bladder was enlarged, adherent to the anterior abdominal wall and surrounding tissues, and its walls thickened from chronic inflammation. It contained a thick purulent fiuid, twenty-two large stones, with one stone completely occluding the cystic duct. We have here an illustration of the fact that even advanced pathologic lesions of the gall-bladder may exist in a patient who complains of nothing but stomach trouble and slight pain. A letter recently received from this patient states that she is feeling better and weighs more than she has for sixteen years.

In making a diagnosis of gall-stone disease the etiologic possibilities should be gone into. It has long been noted that gall-stones often occur after typhoid fever, and are most frequent in women after pregnancy. It is probably also true that any systemic infection which produces toxins that irritate the mucosa of the gastrointestinal tract may be a cause of cholecystitis, which, as we know, in its mild form is a forerunner of gallstones. In the following case the patient's symptoms dated quite definitely from an attack of influenza.

CASE 2.-History.-Mr. D., aged 45. The patient has had recurring pains in the epigastrium and lower abdomen for the past eighteen months; was well up until that time, when he contracted influenza. Since then he has had indigestion and pain in the stomach and lower abdomen. Pain and attacks of indigestion were.irregular and alternated with periods of partial relief. There was no history of colic, cramps or jaundice, but his complexion he thought was slightly tinged at times.

Diagnosis and Treatment.-Operation showed cholecystitis and chronic appendicitis. The appendix was removed and the gall-bladder drained. This case gave a somewhat mixed type of stomach disturbance from both the appendix and the gallbladder and may be an instance of cholecystitis from a general influenzal infection. The experiments of Else show that the gall-bladder is frequently infected through the general circulation and not through the portal system. If we accept his conclusion we can readily believe that a severe systemic infection without intestinal lesion could produce gall-bladder trouble. The operation revealed an appendix that was inflamed and moderately diseased and a gall-bladder somewhat thickened and congested and containing thick dark bile, but no stones. Removal of the appendix and drainage of the gall-bladder were followed by prompt recovery.

This patient was a farmer and had been in gool health until the attack of influenza. So the relation of cause and effect between the influenza, the cholecystitis and the appendicitis may be assumed with apparent justification. It is probable that in such a case the gastric and intestinal mucosa are as much irritated as that of the gall-bladder and appendix, but the poor drainage of these two organs seems to render them unable to throw off the effect of the irritation as the stomach and intestines do.

Gall-bladder disease must be differentiated from ulcer, cancer, gastric neurosis, and reflex disturbance from chronic appendicitis. In ulcer of the stomach and duodenum there is a history of pain in the upper abdomen, coming on from one and one-half to four hours after meals, and relieved by food or by vomiting or by alkalies. The periodicity in ulcer is lacking in gall-stones. There is a definite relation between the taking of food and the relief of pain in ulcers, which contrasts with the sudden, irregular, and fleeting attacks of cholecystitis, which, in most cases, are not influenced in any way by eating. Formation of gas and the feeling of constriction, with belching, constitute a type of disturbance which accompanies gall-bladder trouble and which is not often found in ulcer.

Cancer of the stomach in about 70 per cent. of cares is said to result from ulcer, and its incipiency is diagnosed with great difficulty. A history of previous ulcer of the stomach should warn us of the approach of malignancy, and suggest a careful study of the case and gastric analysis. In cancer, the appearance of the patient, the irregular vomiting and the disgust for food, contrasted with the symptoms and well-preserved appearance of the patient suffering with ulcer or gall-stones, should be of 
some assistance in making a correct diagnosis. Blood is rarely found in gall-bladder cases. In ulcer it is present in one-fourth as against two-thirds of the cases of cancer of the stomach. Gastralgia is found in neurotic individuals, is relieved by pressure, and is not usually attended by nausea or vomiting. It is significant that a more thorough study of the pathology of lesions of the stomach and associated organs of digestion materially reduces the number of patients suffering with so-called gastralgia and other neuroses.

We might be called on to distinguish the girdle pain of locomotor ataxia from an attack of gall-stone colic. Here the Argyll-Robertson pupil, Romberg symptoms, loss of tendon reflex, and other signs of tabes would serve to differentiate.

Disturbance arising from the appendix, shown by gastric indigestion and pyloric spasm, are extremely diffieult of diagnosis from primary gall-stone disease, and the two troubles frequently co-exist.

There may be no tenderness over McBurney's point or any other of the usual signs of appendicitis except a type of continuous stomach trouble. In these cases, however, the history may show an attack of appendicitis. which was not treated at the time of its occurrence, and the patient is able to date his indigestion from this attaek. There is generally a loss of weight and considerable impairment of health. The effect of food on the pain is variable and the pain is usually in the neighborhood of the umbilicus. In appendical drspepsia, its continuous type is in marked contrast to the fleeting, irregular and sudden attacks of gall-bladder trouble, and to gastric ulcer, in which there is generally a definite relation between pain and the taking of food. Cannon, of Boston, has succeeded in producing erosion and ulceration of the stomach by the injection or irritants in the cecum. These experiments would seem to indicate that even organic trouble of the stomach may be produced by disturbance in the region of the ileocecal valve.

The only satisfactory treatment of gall-stones is their surgical removal. Occasionally patients recover after passage of the stone by ulceration through into the bowel or into the stomach, or the patient may go through life a chronic dyspeptic and die of some other disease. It is as much the mission of physicians and surgeons to relieve morbidity as to lower mortality, and though the relation between these two things is not always directly apparent, it nevertheless exists in every case. A patient with indefinite stomach trouble, such as is found in the early stage of gall-stone disease, is more susceptible to other diseases, even if the gall-bladder trouble never assumes a threatening attitude in itself.

The medical profession is practically going through now, in regard to gall-bladder disease, what they have already learned in regard to appendicitis. The modern physician does not think of waiting in appendicitis until an abscess has formed, but recommends that the appendix be removed as soon as it is known to be diseased. So in the case of gall-stones, instead of waiting until the patient has had the early stages and has begun to suffer from colicky pains, vomiting and jaundice, the gall-stones should be diagnosticated in the first stage when the irregular attacks of gastric disturbance, with the feeling of constriction and the formation of gas in the stomach, show that as yet there has been practically no organic change in the liver, gall-tracts, or pancreas. Removal of the stones at such a stage will almost certainly insure a return of the patient to perfect health. 421 West Grace Street

\section{VACCINATION AND SMALL-POX IN JAPAN}

S. KITASATO, M.D.

Director, Institute for Research in Infectious Diseases TOKYO, JAPAY

Since Jenner introduced the practical use of vaccination over a century ago, mankind in general has been well protected from the cruel onslaught of small-pox wherever the process is carried out. We are greatly surprised every now and then to find antivaccinationists among people far advanced in civilization like those of the United States of America. I should, however, never have attempted to make any criticism on their presumption, had not one of them, namely, Dr. Hodge, of Niagara Falls, referred to the facts gathered from our Japanese statistics in his paper in the Twenticth Century Magazine. I may be permitted, therefore, to try to make clear how vaccination is serving to wipe out small-pox in Japan.

\section{EPIDEMIOLOGIC OBSERVATIONS ON SMALL-POX AND ON PREVENTIVE MEASURES IN JAPAN}

The free communication between Japan, China and Corea in earlier days was the source which gave rise to great epidemics of small-pox quite frequently, until at last vaccination was introduced. Japanese history tells us that small-pox was imported for the first time into Kyushyu in the month of February, 123 B. C., after which it gradually spread toward the east as far as Kyoto, causing a great epidemic all. over the country, creating sad havoc, and strewing the high roads with the dead and dying. From this first great epidemic down to 1868, when the restoration of the present Meiji Era set in, about fifty epidemies broke out, each one of which extended over à number of years, sweeping all through the country, diminishing the population considerably and devastating the fertile country everywhere. Towards the end of the Tokugawa Shogunate the measure introduced by Jenner was adopted in Japan, with what favorable results we shall see below. During the ten years from the beginning of the Meiji Era-i. e., 1875-1884the number of patients suffering from small-pox averaged 2, (108.1 per hundred thousand population, while the deaths were only 494.6 , which was deemed to be a remarkable improvement.

One of the greatest epidemics of small-pox during the past forty years broke out in 1885 and lasted three years, with 125,315 cases and 31,960 deaths. The epidemic began to decline in 1888 . It reappeared in 1892 and again lasted three years. During this second outbreals 88,095 cases were recorded, of which 23,603 patients died. The third outbreak extended over two years, $1896-$ $189 \%$, with 52,650 cases and 15,664 deaths. During the next ten years, a few cases were imported from China every now and then, without any ensuing serious outbreak. Since 1900 , the cases in the whole empire were remarkably few, until in 190\%, when the disease reappeared at Kobe. This caused an uncommonly severe epidemic, which spread all through the empire. It began to die out in the spring of 1908. During this fourth epidemic 19,101 cases and 6,273 deaths were reported. This outbreak, however, completely subsided by July of the same year, without any trace left. The diagram inserted shows these epidemics most clearly.

Let us now turn our attention to what has been done to avoid the wretched results brought about by small-pox in Japan. In olden times when people were ignorant of what measures they should apply, they resorted to 